\title{
BENITO PÉREZ GALDÓS Y SU NOVELA TORMENTO: ALGUNAS CONSIDERACIONES SOBRE LA MISMA
}

\author{
Ricardo Szmetan*
}

\section{Introducción}

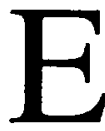
n la época actual, se tiende a olvidar que muchos de los mayores éxitos literarios del siglo XIX -en particular los novelísticos- fueron primero editados en forma de folletines en periódicos de larga difusión. A veces, además, hasta eran preparados en forma especial para la venta callejera en tiradas diarias o semanales antes de ser publicados en forma de libro, si es que finalmente salían en ese formato, después de todo. Esta forma particular de literatura, llamada en España de cordel, ha tenido un éxito a través del tiempo a todas luces extraordinario y ha sido muy diseminada como parte de la literatura popular, más allá de su origen y maneras típicas de la época romántica.

Por mucho tiempo, este tipo de literatura ha sido poco estudiada por los especialistas, que la consideraban un género un tanto subalterno y de circunstancias. Sin embargo, hoy en día, con el interés creciente en analizar a la literatura en todas sus facetas -lo dejado antes entre las sombras-, hay un nuevo, y marcado, interés en el asunto. Además, ha sido de esta manera que por mucho tiempo muchos escritores han intentado ganarse la vida. Sin duda que la división del trabajo, propia consecuencia de la Revolución Francesa y luego de la Industrial, tiene mucho que ver con la situación de casi indefensión que se encontraba el escritor a partir sobretodo de finales del siglo XVII.

* University of West Indies-Barbados. 
Subsecuentemente, se agrava la situación del escritor con el auge del naciente capitalismo al casi terminarse el mecenazgo, que pese a todos sus defectos había ayudado al desarrollo de las artes, pero que ya se lo consideraba más propio de épocas pasadas que de la moderna. Todo esto no mejora -por cierto- la situación social y económica del escritor. Tampoco hablar de lo que sucede en nuestra época postmoderna, con su gusto por lo fragmentario y lo heterogéneo, con la creciente disolución de mucho de lo considerado anteriormente como canónico o que respondiese a normas previamente fijadas por un orden determinado a priori. La realidad hoy día está hecha por muchos referentes, y con la globalización y los avances tecnológicos, esta tendencia a la fragmentación tiende a crecer cada vez más, y el rol del autor continua a perder preponderancia.

En muchos sentidos, el amorfo mercado es el que decide la suerte de la mayoría de los artistas, librados a su suerte y debiendo - para poder subsistir-tener que vender su fuerza de trabajo como periodistas, publicando mientras tanto de forma irregular su obra creativa, considerada por el nuevo orden como un valor de cambio más, dirigido a producir material para un potencial mercado de lectores que desde antes de la época de Benito Pérez Galdós (1843-1920) iba creciendo constantemente con el aumento poblacional de las ciudades, lo que permitía la creación de gran cantidad de nuevos medios de difusión. Para el escritor, las mayores posibilidades de colocar su obra no resultaba necesariamente en mejores condiciones de vida, ya que los medios de producción vigentes no valorarán el trabajo artístico más que como un referente entre otros en el orden de las cosas, facilmente sustituible al menor problema o cambio de gusto por parte del público, que casi siempre prefiere la novedad a cualquier otra consideración sobre la calidad de la obra en sí.

Desde siempre, muy pocos han podido vivir con el usufructo de la creación pura, contentándose los trabajadores del espíritu - las más de las veces- en tratar de aprovechar el mayor circuito de lectura que el periodismo creaba, bien que sacrificando seguido calidad por cantidad, obligados de esta manera por la forzada periodización de los medios de difusión. Muchas veces existía la obligación de producir la exacta cantidad de palabras para llenar los espacios requeridos. Si ya antes, en la literatura europea moderna, se conocía casos famosos como el de Honoré de Balzac (1799-1850), de ser uno de los primeros profesionales reconocidos de las letras que escribía a tanto la página, pensando en el público lector que lo leería, en América estaba un escritor de la calidad de Edgar A. Poe (1809-1849), quien acostumbraba a publicar sus cuentos en forma fragmentada en los diarios del norte de su país, esperando vivir con el usufructo de ellos.

Mientras tanto, en el otro lado del continente, bien al sur en la naciente Argentina, el abanderado de un tardío romanticismo en el país, Esteban Echeverría 
(1805-1851), sacaba poco antes de morir, en forma de folleto, su famoso largo cuento político antirosista $\mathrm{El}$ matadero, el primero creado en el país y que recién fue publicado en forma de libro en 1938. Otro famoso desterrado, José Mármol (1817-1871), publicó en partes su recordada novela Amalia, en 1844, siendo la misma también la primera novela conocida del pais. Hasta el poema nacional: el Martín Fierro (1872 ida; 1879 vuelta), de José Hernández (1834-1886), se publicó en varios diarios de segundo orden como un folletín serial, ganando con justicia una extraordinaria popularidad entre los gauchos, aun entre los que no sabían leer -la gran mayoría-, al ser recitado en las pulperías y vendido en los almacenes como un artículo más de consumo. La tradición cuenta también que se acostumbraba a pedirlo junto con la yerba y el azúcar, tanta era su popularidad entre la gente.

Lo mismo pasó con la obra del popular periodista y novelista Eduardo Gutiérrez (1851-1889), quien con su recordado dramón Juan Moreira (1884), ayudó también a la creación del teatro nacional argentino, al ser llevada la obra a las tablas por los hermanos Podestá. Entonces, por primera vez actuaban en papeles protagónicos actores argentinos y no sólo los españoles. Esta familia, cuyos más conocidos integrantes eran miembros de un circo ambulante, aprovecharon el filón melodramático de un perseguido por la justicia, para conseguir un extraordinario y nunca igualado éxito popular. Hasta el propio Domingo F. Sarmiento (1811-1888), luego presidente de la Nación, publicó de la misma manera su híbrido, pero extraordinario, ensayo-novela Facundo (1845), sobre el caudillo federal de La Rioja, Facundo Quiroga, y sobre muchos otros aspectos de la naciente república del sur y de su plan para poder desarrollarla, de acuerdo a un plan más racional que el que por entonces había por allí.

\section{Las características y trama de Tormento (1884)}

Como se ha mencionado, en España se acostumbra a denominar literatura de cordel a la venta callejera -muchas veces por suscripción- de novelas fragmentadas en capítulos llamadas justamente folletines, por venir seguido en forma de folletos. La novela Tormento es un ejemplo de este tipo de literatura, con el agregado de que encarna a grandes rasgos el concepto que tenía Galdós de la novela realista y la relación no siempre clara entre ficción y realidad, problema que en verdad se plantea en mayor o menor medida todo autor de novelas. Por eso, esta obra es de importancia dentro del mundo novelístico galdosiano y con respecto a sus teorías sobre la novela en general, y sobre la idea de los folletines en particular y de cómo llegar al gran público lector. 
Hay que aclarar que lo que más quiso mostrar Galdós en Tormento es que la realidad, y no la ficción, es la que domina la vida, aunque algunos quisieran o creyesen que fuera al revés. Esto es lo contrario de lo que afirma el personaje Ido en la obra: "¿Ves, ves? La realidad nos persigue. Yo escribo maravillas; la realidad me las plagia" (p. 13-14). Cuando al comienzo de la novela se encuentran de nuevo Ido y Aristo, que habían sido personajes en novelas anteriores del propio Galdós, lo cual era una característica suya y por otra parte bastante común de la época, ya que muchos de estos escritores realistas trataban de transcribir lo más fielmente los rasgos de la sociedad en una secuencia de novelas, aquél le cuenta que está ya en plena actividad escribiendo novelas por entregas; no ya una por vez, sino a veces hasta tres, como se esperaba de quien dependía de la escritura para mal vivir. Los personajes son aquellos que se pueden esperar en este tipo de literatura popular por lo demás escapista: "Hombres embozados, alguaciles, caballeros flamencos y unas damas, chico, más quebradizas que el vidrio y más combustibles que la yesca" (p. 10).

Ahora, Ido se ocupa de una historia de la que ya tiene catorce repartos y que continuará hasta que el editor diga basta; es decir cuando comience a mermar la venta de la misma. Se trata de una obra con "mucho sentimiento, que haga llorar a la gente y que esté bien cargada de moralidad" (p. 11), en la cual: "Hay dos niñas bonitas, pobres, se entiende, muy pobres, y que viven con más apuro que el último día de mes... Pero son más honradas que el Cordero Pascual" (p. 11). Como se verá luego, ni Refugio ni su hermana Amparo, alias Tormento, son lo que se podría llamar dechados de virtud virginal, sino más bien todo lo contrario.

Luego del comienzo del diálogo entre Ido y Aristo, que justamente se puede denominar melodramático, se ve como la continuación de la novela es totalmente diferente a la trama que Ido estaba pensando realizar. Esta es la mejor demostración del deseo de Galdós de contradecir en él los ideales folletinescos por entonces de moda. Así se puede hablar de dos obras en una: La novela folletinesca tradicional que prepara Ido y la novela Tormento de Galdós, folletinesca también en su forma e idea, pero que desmiente los preceptos considerados como canónicos por la literatura del género. José Montesinos fue de los primeros críticos en descubrir el sentido irónico que campea en Tormento:

Y aquí viene la diablura de Galdós: dos mozas así existen de verdad (se refiere a Refugio y Amparo) en Madrid, y casi las hemos conocido. Ya tuvimos noticia de ellas por El doctor Centeno, a una de ellas va a llevar Felipe un mensaje de su amo, y resulta que ellas son los modelos de Don José, pues son sus vecinas y en su vida se inspira para su novela. A Galdós no le 
duelen ni estorban estas casualidades; antes las procura y explota siempre que puede; nunca mejor que ahora, en que a todas luces ironiza. Un folletín realista no podía menos de resultar un folletín irónico, como un libro de caballerías escrito por Cervantes (p. 95).

Le cabe a Alicia G. Andreu el mérito de haber visto claramente no sólo la ironía latente en Tormento, en cuanto a ejemplo de novela antiromántica, sino la implícita parodia que se hace a la industria folletinesca en su conjunto: "La proximidad que vimos en la primera novela (La desheredada) se ha transformado en la segunda y en su lugar nos encontramos con el autor de Tormento en una actitud de parodia frente a toda la industria folletinesca y frente a algunos de los valores que componen el código femenino de la literatura de consumo" (p. 134).

Por su parte, Germán Gullón reconoce también la ironía que se nota a lo largo de toda la novela: “¿Cómo surge la ironía? A cada novela se le ha puesto un final convencional. A la de Ido: el de la virtud triunfante; a la del narrador: el suicidio de Amparo; a la del autor implícito: la indignación de La de Bringas" (113-114). Pero los finales "son irónicos a la luz de lo que va a suceder" (p. 113114). La trama que sigue a continuación, se encarga de desvirtuar otros sugestivos comentarios que Ido realiza en el primer capítulo de Tormento. Por ejemplo:

Mis heroinas tienen los dedos pelados de tanto coser, y mientras más les aprieta el hambre, más se encastillan ellas en su virtud. El cuartito en que viven es uno. Ni Refugio o Amparo se ganan la vida cosiendo, ni menos se aferran a su virtud en los crecientes momentos de necesidad económica por la que pasan. Refugio, que vende sus encantos a quien pueda pagárselos, intenta en un principio esconder a su hermana el verdadero origen de sus entradas de dinero: ¿Soy yo mala? No. Me preguntas que como he comprado las botas y he arreglado mi vestido. Pues te lo diré. Estoy sirviendo de modelo a tres pintores... Modelo vestido, se entiende. Gano mi dinero honradamente... (p. 69-70).

A lo cual la hermana le responde con una idea propia de folletín: "Mejor sería que cosieras y estuvieras en casa.¡Ay!, hermana, tú acabaras mal..." (p. 70). Refugio sabe bien que su hermana no es moralmente mucho mejor que ella: "Si fueras mejor que yo, pase -observo la díscola Refugio-, revolviéndose provoca- 
tiva, irritada, blandiendo su argumento, cual si fuera una espada, ante el pecho indefenso de su hermana; pero como no lo eres..." (p. 70). Es de lamentar que un personaje femenino tan interesante como es el de Refugio no tuviese un papel más protagónico en Tormento; ya que ella tiene el coraje de sus actos, aparte de no ser nada hipócrita; al contrario, representa un tipo valiente de mujer que le tocó vivir en una sociedad con normas morales de folletín. Ella se rebela contra los sermones y prédicas huecas de su hermana: "No prediques, que eso no conduce a nada. ¿Por qué es mala una mujer? Por la pobreza... Tu has dicho: si trabajas... ¿Pues no he trabajado bastante? ¿De qué son mis dedos? Se han vuelto de palo de tanto coser. ¿Y qué he ganado? Miseria y más miseria..." (p. $81)$.

En la última cita, vemos en boca de Refugio la respuesta que tal vez quiso darle Galdós a la ideología representada por Ido. Refugio está lejos de querer tener el papel de pobre chica honrada que se pasa la vida cosiendo. Para más, lejos de aceptar su pobreza se rebela contra ella. Lo que pide es no ser juzgada por las consecuencias de su conducta, sino asegurarse las necesidades básicas:

...Comida, la ropa, y nada tendrás que decir de mi. ¿Qué ha de hacer una mujer sola, huérfana, sin socorro ninguno, sin parientes y criada con cierta delicadeza? ¿Se va una a casar con un mozo de cuerda? ¿Qué muchacho decente se acerca a nosotras viéndonos pobres?... ¿La costura, para qué sirve? Para matarse... (p. 81).

Aquí vemos bien ejemplificada la contradicción entre una ideología conservadora que trata de esconder, a través de la elaboración de sueños románticos, una realidad que es menos rosa. Es, de alguna manera, la contraposición de la visión realista con la visión romántica. Si en la época en que Galdós escribe Tormento, la visión romántica en la literatura sufría un indeclinable deterioro, lo mismo puede pensarse, en menor medida, con la novela por entregas, derivada en el fondo, y forma, de aquella. Aun así, este tipo de novela popular respondía a una real necesidad que cierto público mayoritario tenía -especialmente de mujeres- por una lite-ratura escapista, que existirá siempre, y no debe pensarse en que haya nada de malo en que ocurra así. Al contrario, luego el cine y la televisión remplazarán a estos folletines como medio de difusión que siempre siguirá una misma línea argumenta-tiva, con bastante éxito a decir verdad.

Para el un tanto rígido y bastante formal Galdós, esos lectores eran de 
paco-tilla y "formaban la atmosfera que envuelve las malas obras," y los que "hacen copioso abasto de la poesía hinchada y de relumbrón, y regalan su estómago con la indigesta novela que fabrican ciertos escritores" (La Nación 1868, y Andreu 97). Si Ido ve tanto a Amparo como a Refugio desde una visión romántica idealizada, Galdós las tratará desde una visión realista. Lo que principalmente se percibe en Tormento, es que la realidad destruye la ilusión romántica que la mayoría de los personajes tienen. Y esto se nota en personajes de por sí paradigmáticos, cuyos nombres se pueden asociar a alguna cualidad que tienen, o parodiándolos cuando su comportamiento es contrario a lo que su nombre de pila indicaría.

Por ejemplo, Caballero desea a Amparo a través de la idea que se hace de las heroinas románticas, de las que tiene la imaginación llena. En la visión romántica, el mismo nombre de Caballero dá a pensar sobre ciertos rasgos físicos y morales que se supone debería tener el galán de la trama. La visión realista de Galdós se encarga de desmentir una vez más la premisa romántica; además, Caballero no es tampoco joven como se acostumbraba a que fueran los galanes en las novelas folletinescas: "Agustín Caballero no era ya mozo; pero, sin duda, el cansancio y los afanes de una penosa vida tenían más parte que los años en la decadencia física que expresaba su rostro" (p. 34).

El ejemplo de Caballero es importante para mostrar como Galdós sacaba a los personajes de Tormento del paño de las novelas por entregas utilizando, paradójicamente, sus mismos elementos constitutivos, y así, la misma estructura de la novela parece copiada de otras del género. Véase también como mayormente los finales de capítulo no significan el fin de una acción determinada, como era la costumbre en ellas. En las novelas por entregas se intentaba así alargar la acción, de manera que el lector mantuviese el interés y continuase a adquirir los capítulos subsiguientes de la obra. Definitivamente, en su apariencia exterior, Tormento tiene todas las características que se espera de una novela por entregas, pero va más allá de ellas al parodiarlas también.

Veamos algunas de las características que distinguen a ese tipo de obras, y que corresponden con las que también se leen en Tormento. Ya que la abrumadora mayoría de los lectores de esas obras eran del género femenino, la lectura que se esperaba -y se provocaba- era principalmente la de un nivel emotivo y sentimentalista, jugándose con el efecto sorpresa y la continua tensión con muy calculados y medidos recursos efectivistas. De ahí que los capítulos pudiesen coincidir con el final de una entrega y terminasen o con una ruptura o con la suspensión del hilo narrativo, quedando los personajes en un trance crítico cuya resolución se esperaba con impaciencia al día siguiente.

Volviendo a Caballero, se puede decir que sin duda sus ideas generales 
son más bien conservadoras. Desea formar un hogar y vivir una vida retirada y tran-quila, siendo folletinesco su ideal de la mujer para casarse, debiendo ser ésta, según su parecer, casta y pobre. Su interés por Amparo está prefigurado por la propaganda diseminada por las clases dominantes, interesadas en crear un público lector que aceptase sus fabricaciones arquetípicas como propias. Rene Girard, quien ha estudiado detenidamente y como pocos este tipo de manipulaciones, afirma como: " $i N o u s$ nous croyons libres, autonomes dans nos choix, que soit celui d'une cravate ou celui d'une femme, illusion romantique! En realite nous ne choisissons que des objects deja desires par un autre" (p. 5).

Como queda dicho, es interesante destacar como los nombres de ciertos personajes son característicos para mostrarnos algunas particularidades salientes de sus personalidades, con el deseo -casi siempre encubierto- de ironizar el ideal romántico que prefiguran. Por ejemplo, y como su nombre lo indica, Ido del Sagra-rio parece vivir completamente fuera de la realidad. Amparo y Refugio son las dos caras de una misma moneda, ya que si bien buscan amparo y refugio de diferente manera, el fin que buscan es el mismo. Don Francisco de Bringas y Caballero es, como su nombre lo indica, un caballero, y puede contraponerse tranquilamente su figura a la del indiano Agustín Caballero, que durante la mayoría de la novela apa-rece como el prototipo del héroe romántico, para sólo mostrar al final su verdadera personalidad al aceptar como amante, pero no como esposa, a la ya ante sus ojos pecaminosa Amparo.

Por otra parte, el verdadero carácter de Rosalía Pipaon Calderón de la Barca, se verá con más precisión en la siguiente novela de Galdós del año posterior: Las de Bringas, cuando se venderá por dinero. En Tormento vemos ya varias características suyas desfavorables, de las cuales no es la menor el gusto por el lujo. Rosalía es la que representa mejor el modelo que las clases dominantes deseaban tener por medio de la difusión de la literatura folletinesca. No perteneciendo por cuenta propia a la nobleza, hace suyos los principios de aquélla. El propio Galdós se encarga al principio de la novela de presentarla apropiadamente:

Para esta señoras había dos cosas divinas: el Cielo, o mansión de los elegidos, y lo que en el mundo conocemos con el lacónico sustantivo de Palacio... Cualquier frase, palabrilla o pensamiento contrarios a la superioridad omnímoda y permanente de la Casa Real entre todo lo creado por Dios y los hombres, ponía a las buena señoras tan fuera de sí, que hasta su hermosura parecía como se eclipsaba y oscurecía. (p. 18) 
Recordemos como Ido le hablaba a Aristo de su deseo de incluir en su novela por entregas a "una duquesa más mala que la Landre, la cual quiere perder a las chicas por la envidia que tiene de lo guapas que son..." (p. 12). Pues Rosalia, que quiere y mal puede, es la versión realista de esa duquesa cuya riqueza y posición social le permiten muchas cosas, entre las cuales, por cierto, la de ser mala. Si bien es evidente el trasfondo folletinesco ironizado en Tormento, también se la puede asociar al tipo de acción representado por el teatro más popular de la época, con sus personajes voluntariamente distorsionados para mejor ser caracterizados. Tormento es una novela cuya estructura y problemática central la hermanan con los conceptos de teatro y teatralidad. Debido a su construcción insólita, se encuentra en la encrucijada entre una novela y una obra de teatro. Asimismo, en ella coexiste la teatralidad entendida en su significación y aparatosidad o amplificación exagerada de una actitud teatral vivida fuera de las tablas.

Resulta importante destacar, por último, que en los últimos años el interés de la crítica ha vuelto a renacer por esta obra importante en la producción general de Galdós, y es de esperar que este interés no decrezca en el futuro, ya que a lo menos Tormento es bien representativo del pensamiento galdosiano referido a las novelas por entregas, del cual fue unos de los más fieles representante.

\section{RESUMEN}

Al examinar la novela Tormento (1884) de Benito Pérez Galdós (1843-1920) y enfocar sus características folletinescas, se pretende rescatar la importancia de la literatura de cordel en el escenario literario español del siglo XIX, así como recuperar la discusión galdosiana sobre la relación entre la realidad y la ficción.

Palabras-clave: Benito Pérez Galdós, Tormento, literatura de cordel, ficción realista.

\section{RESUMO}

Ao examinar o romance Tormento (1884), de Benito Pérez Galdós (1843-1920), e enfocar suas caraterísticas folhetinescas, pretende-se resgatar a importância da literatura de cordel no cenário literário espanhol do século XIX, bem como recuperar a discussão galdosiana sobre a relação entre a realidade e a ficção.

Palavras-chave: Benito Pérez Galdós, Tormento, literatura de cordel, ficção realista. 
SZMETAN, R. Benito Pérez Galdós y su novela Tormento...

\section{REFERÊNCIAS}

ANDREU, A. G. Galdós y la literatura popular. Madrid: Ed. Sociedad General Española de Librería, 1982.

ELIZALDE, I. Pérez Galdós: su novelística. Bilbao: Ed. Ubicaciones de la Universidad de Desto, 1981.

GALDÓS, B. P. El doctor Centeno. Madrid: [s.n.], 1905. Tomento. Madrid: Ed. Alianza, 1984.

. Colección de poesías de don Rafael M. Fernández. La Acción, v. 7, n. 22, 1868.

GIRARD, R. Mesonge romantique et verite romanesque. Paris: Ed. Grasset, 1961.

GOLD, H. Tormento: vivir un dramón, dramatizar una novela. Anales Galdoseanos, n. 22, 1987.

GULLÓN, G. El narrador en la novela del siglo XIX. Madrid: [s.n.], 1976.

RICARD, R. Aspects de Galdos. Paris: Ed. Presses Universitaires de France, 1963.

MONTESINOS, J. Galdós. Madrid: Ed. Castalia, 1969.

YNDURAIN, F. Entre la novela y el folletín. Madrid: Taurus, 1970. 